\title{
MENELEU CAMPOS - OS QUARTETOS DE CORDAS
}

\section{MENELEU CAMPOS - THE STRING QUARTETS}

\author{
Odair Aparecido de Paula \\ Associação Mogiana de Paleografia \\ odairpaula@hotmail.com \\ Claudio Cruz \\ Orquestra Sinfônica Jovem do Estado de São Paulo \\ conductorclaudiocruz@gmail.com
}

\section{Resumo}

$\bigcirc$ presente artigo aborda os quartetos de cordas de Octavio Meneleu Campos (1872-1927), obras do repertório camerístico brasileiro: Quarteto $n^{\circ} 1 \mathrm{em} \mathrm{Sol} \mathrm{maior} \mathrm{(1899),} \mathrm{Quarteto} \mathrm{no} 2 \mathrm{em} \mathrm{Lá}$ maior (1899), Quarteto n'o $3 \mathrm{em}$ Ré maior (1901) e Quarteto $n^{\circ} 4 \mathrm{em}$ Mi maior (1902). Na metodologia temos as diversas fontes primárias fornecidas pelo Museu da Universidade Federal do Pará, realizamos uma edição crítica que está em estágio de editoração, bem como uma busca nos periódicos de época sobre a trajetória do compositor e seu repertório, especialmente os quartetos de cordas. Evidenciamos a maestria do compositor na confecção dos quartetos e a importância de sua inclusão no repertório camerístico brasileiro. Discutimos ainda os problemas na recepção de sua obra.

Palavras-Chave: Meneleu Campos; edição musical; Quarteto de cordas; Música de câmara brasileira. 


\begin{abstract}
This article deals with the string quartets of Octavio Meneleu Campos (1872-1927), works from the Brazilian chamber repertoire: Quartet $n^{\circ} 1$ in $C$ major (1899), Quartet $n^{\circ} 2$ in A major (1899), Quartet $n^{\circ} 3$ in D major (1901) and Quartet No. 4 in E major (1902). In the methodology we have the various primary sources provided by the Museum of the Federal University of Pará, we carry out a critical edition that is in the editing stage, as well as a search in periodicals about the composer's trajectory and his repertoire, especially the string quartets. We highlight the composer's mastery in making quartets and the importance of their inclusion in the Brazilian chamber repertoire. We also discuss problems in receiving your work.
\end{abstract}

Keywords: Meneleu Campos; Music edition; String quartet; Brazilian chamber music.

\title{
Agradecimentos
}

Agradecemos a Vicente Salles, pela referência aos quartetos de Meneleu Campos, na década de 1990, determinante para que solicitássemos ao Museu da Universidade Federal do Pará (UFPA) os manuscritos dos quartetos e iniciássemos uma edição crítica.

Agradecemos também a Rubens Russomanno Ricciardi, por suas sugestões e comentários, tendo nos ajudado ainda na elaboração crítico-conceitual deste artigo. 


\section{Introdução}

Apresentamos aqui um estudo sobre os quartetos de cordas de Meneleu Campos, momento em que foram compostos, influências relevantes que determinaram sua poética, fontes históricas que nos aproximam de uma biografia do compositor a partir de notícias de jornais, revistas e publicações específicas mais recentes. Mencionaremos também a metodologia aplicada na realização de uma edição crítica e a gravação integral desses quartetos pelo Quarteto Carlos Gomes, junto ao Selo Sesc, lançada em setembro de 2021. 


\section{Meneleu Campos - dados biográficos}

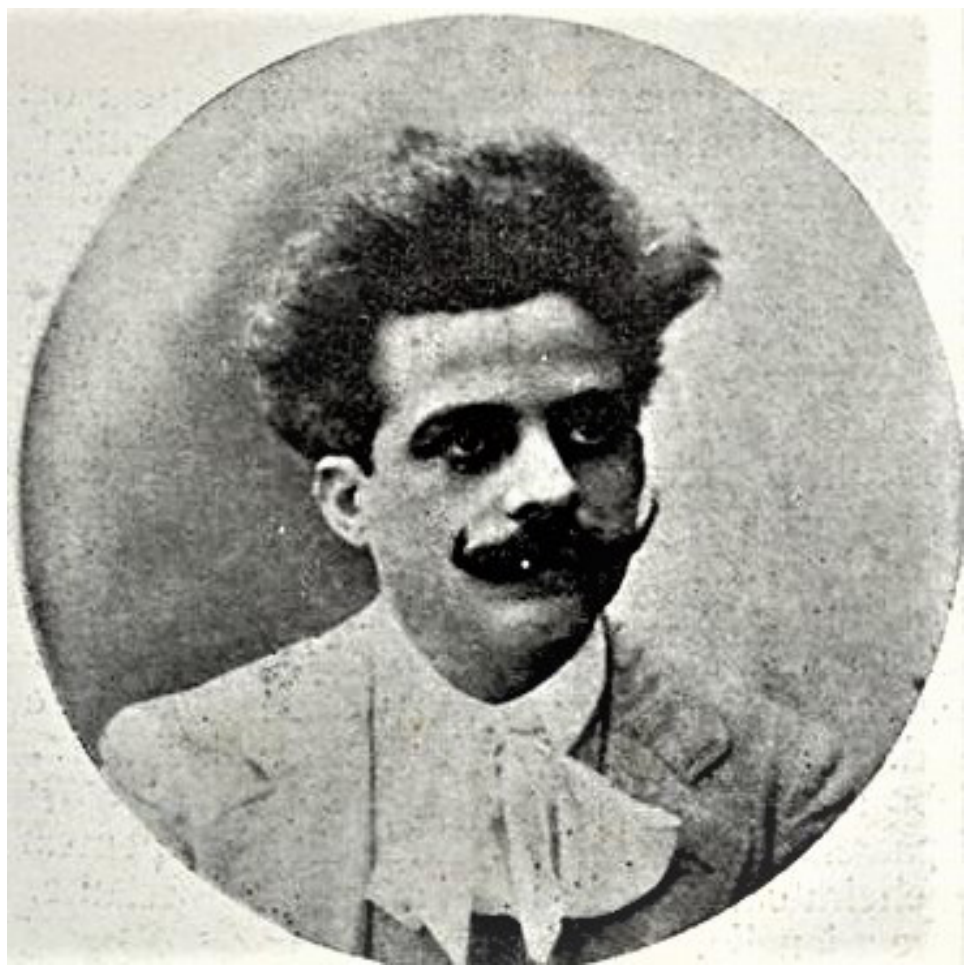

Revista Fon Fon (Rio de Janeiro), Ano 3, nº 30, 27/07/1919, p. 3.

Octavio Meneleu Campos (Belém, 22 de julho 1872 - Niterói, 20 de março de 1927), além de compositor, foi também pianista, violinista, maestro, professor e dirigente de instituições de ensino de música, tendo sido um empreendedor em diversos projetos. Filho de João Marinho Campos e Adelaide da Costa Campos, teve como irmãos João Coelifilius de Campos, Deoclecio Marinho de Campos, Izabel de Campos Calhieiro, Adelaide Rivia de Campos Neves, Ercilia Guiomar de Campos e Cecilia de Campos Parentel

I Jornal do Commercio (Belém), 23/10/1911, p. 3. 
Seu pai, João Marinho Campos, natural de Sergipe, fundou, em Belém, a Casa Capesina², tendo sido ainda diretor do Banco de Belém do Pará 3 e da Fábrica de Cerveja Paraense 4 . Também atuou como mecenas, apoiando concertos beneficentes ${ }^{5}$ em Belém e chegando a ser membro da Comissão de Artes da Associação Paraense Propagadora das Belas Artes 6 . Em 1911, contando com 65 anos de idade, ainda ativo nos negócios e na política e ocupando o cargo de coronel da Guarda Nacional, suicidou-se após receber a notícia da falência da Firma Enrico Tucci, Junior \& Companhia, onde havia feito grandes investimentos?

Passando a infância num ambiente artístico, Meneleu Campos foi aluno de sua mãe, a pianista Adelaide da Costa Campos, e do violinista baiano radicado em Belém, Adelelmo do Nascimento, seu grande incentivador nos primórdios de sua carreira. Sua mãe foi atriz e cantora em Belém. Em 1859, atuou na peça Probidade, no Teatro Providência ${ }^{8}$. Como coralista, a 7 de setembro de 1859, no mesmo teatro, cantou o Hymno da Independencia'. Atuou como cantora até o início da década de 1860, apresentando-se ao lado do cantor Arcenio. ${ }^{10}$ Como também tocava piano, ela foi responsável pelos primeiros passos de Meneleu Campos na música. Faleceu em 1919, em Belém." Meneleu Campos dedicou sua obra 15 de novembro de 1889 ao seu professor Adelelmo do Nascimento 12, o qual atuou como "professor de orquestra" (músico) no Theatro da Paz, em $\left.189\right|^{13}$.

2 Diário de Belém, 04/04/1880, p. 3.

3 A República (Belém), 18/02/1890, p. 2.

4 Estado do Pará (Belém), 09/09/1911, p. 3.

5 Diário do Belém, 24/05/1887, p. 3.

6 Folha do Norte (Belém), 27/03/1896, p. 3.

7 Jornal do Commércio (Belém), 23/10/1911, p. 3.

8 A Ephoca (Belém), 03/12/1859, p. 3.

9 Gazeta Official (Belém), 06/09/1859, p. 4.

10 Gazeta Official (Belém), 3 1/05/1860, p. 3.

11 Jornal do Commércio (Belém), 06/08/1919, p. 2.

12 Diário de Notícias (Belém), 20/09/1891, p. 2.

$13 \bigcirc$ Liberal do Pará (Belém), 08/09/1880, p. 1. 
Meneleu começou a compor precocemente, aos 16 anos de idade. Chegou a cursar Direito por algum tempo no Recife. Contudo, optou por se dedicar exclusivamente à música. Em meados de 1891, após estudos preparatórios sob orientação de Andrea Guarneri, passou a estudar no Conservatório de Milão com um dos mais importantes professores de composição da época, Vincenzo Ferroni, ex-aluno de Jules Massenet. Em Milão, por quase uma década, Meneleu Campos progrediu em seus estudos, principalmente de composição, além de piano, violino, teoria musical e regência. Em Belém do Pará, desde 1900, passou a atuar em escolas de música como professor e diretor, tais como o Instituto Carlos Gomes e outras instituições privadas que fundou. Também regendo por diversas vezes no Theatro da Paz, intercalou sua vida profissional em Belém com estadas em Milão (1903), Rio de Janeiro (1909), Paris (19/3) e Lisboa (19/4-19/5), entre outras viagens de menor duração.

As composições de Meneleu Campos, além do destaque na imprensa local, também eram editadas e vendidas, como Noite em Claro, composta em 1890, publicada e comercializada pela casa Costa e Silva. Bem relacionado nos meios políticos e artísticos, Meneleu Campos se aproximava de figuras importantes de seu tempo, como o Dr. Paulino de Brito, a quem dedicou a obra e cujo livro homônimo the serviu de inspiração. ${ }^{14}$

Segundo Vicente Salles, Meneleu Campos obteve sucesso com sua valsa Cecy, em 1891, que motivou o seu professor, Adelelmo do Nascimento a pleitear, junto ao governo republicano, uma bolsa de estudos para que ele fosse estudar na Europa (apud COSTA, p. 37). Contudo, seu pai, homem bem sucedido financeiramente, além de incentivá-lo a seguir na carreira musical, que o fez abandonar o curso de direito, em Recife, resolveu custear a sua ida para a Itália, onde se

14 O Democrata (Belém), 25/07//890, p. 1. 
matriculou no Conservatório de Milão (fundado em 1807, dos maiores e mais importantes na Europa).

Meneleu Campos embarcou para a Itália a $1^{\circ}$ de maio de 1891. Durante o curso, manteve correspondência com Adelelmo do Nascimento, seu ex-professor, o qual acompanhava, agora de Manaus, seu desempenho artístico-acadêmico no Conservatório de Milão. Prova disso foi a carta que Adelelmo do Nascimento remeteu ao pai de Meneleu, João Marinho de Campos, documento este levantado por Vicente Salles:

As notícias que tenho tido dos progressos rápidos e profundos que tem feito Meneleu no Conservatório, a estima, e o conceito que ele goza entre os seus professores e condiscípulos e a sociedades de verdadeiros artistas e amadores que frequenta, assim como a estima particular de Carlos Comes, tudo isso me tem feito transbordar o coração de alegria e orgulho, cada vez mais estou convencido que tive razão quando the sugeri a ideia de mandá-lo para a Europa, assegurando-lhe que Meneleu era dotado de um talento superior $e$ de bastante força de vontade para vencer todas as dificuldades desta arte imensa e espinhosa, e tornar-se um músico distintíssimo, uma verdade glória para a família, sua terra natal e sua pátria (apud COSTA, 2011 , p. 39).

Durante seus estudos em Milão, de 1891 a 1899, a produção musical de Meneleu Campos não raramente ganhava destaque na mídia belenense: 


\section{Menelen Campos}

Este nosso talentoso conterraneo, que estud, musica actualmente com grande brilhantismo em Milao, e cuja actividade é attestada pelas bellas composiçoes que envia com frequencia a sua terra natal, acaba de nos contemplar mais uma vez na distribuicalo dos seus valiosos mimos.

Intitula-se-Melancolia - a nova composiçà, que é ua andante para piano e violino.

Meneleu Campos possuo uma inspiraça cheia de viģo o fruscura, e em cada composiça nova que publica, revéla os grandes progressos que faz, pois mostrase cada vex mais conhecedor dos segredos da sua hoje, mails que nunca, diffcilima arte.

Uma observagalo que nao póde deixar de tazer quem cunhece as composiçes de Meneleu, é que ellas nao teem nada de trivial, o manifestam progressivamente uma originalidade mais o mais accentuada o pujante.

Tao teliz complexo de qualidades levarao certamento o joven compositor paraense muito longe, no camiaho glorioso que encetou.

Reccmmendando aos nossos dibetlanti a nova joia musical, felicitauos ao joven autor e a seu extremoso pae sr. Marinho de Campos.

Diário de Notícias (Belém), 20/03/1892, p. 2. 
Também na próxima ilustração abaixo é noticiada a composição Melancolia para piano e violino, com destaque aos avanços na qualidade de suas composições que enviava com frequência "á sua terra natal". É possivel que um dos membros de sua abastada família, residente em Belém, distribuísse suas as obras entre os jornais da cidade, dada à frequência das publicações.

\section{MALINCONIA} $=$

Con o titulo atima recebemos un lindissino andmite para violino e piano forte, mimosa producço do nosso distincto conterraneo Meneleu Campos, actualmente en estudos na Italia.

Agradecamos a lembrança.

A República (Belém), 19/03/1892, p. 2.

Até mesmo as notas escolares de Meneleu ganhavam destaque na imprensa brasileira, em razão das avaliações obtidas ao final do $2^{\circ}$ ano da disciplina Harmonia. A obtenção da elevada nota em Harmonia, 9,75, no Conservatório de Milão, portanto, era considerada um grande feito à época. 


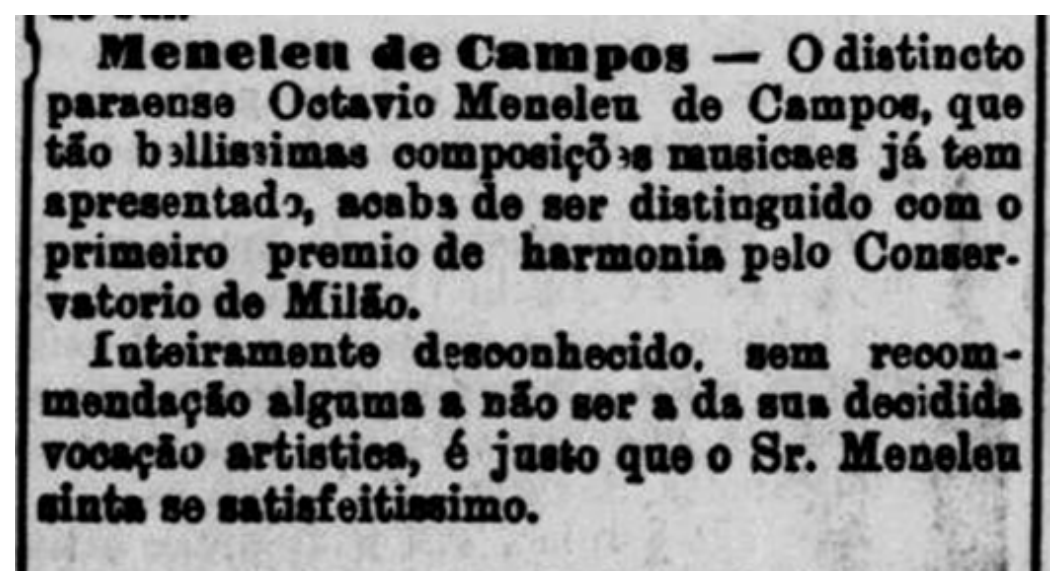

Jornal do Recife, 03/08/1892, p. 3.

Seu prestígio no Brasil, mesmo estando longe, pode ser atestado na execução de composições que foram produzidas em Milão e enviadas ao Brasil, como a Marcha Triumphal, orquestrada e executada pelo maestro e compositor José Cândido da Gama Malcher (Belém, 18531921), com o consentimento de Meneleu, em benefício da fundação do Orphelinato Paraense ${ }^{15}$, ocorrida a 15 de agosto de $1893^{16}$ - um orfanato municipal de Belém, o qual abrigou e educou centenas de meninas desvalidas até 1911 .

Sempre atento às notícias do Brasil, Meneleu Campos compôs uma Marcha Fúnebre, por ocasião da morte de Antônio Carlos Comes. No Brasil, a obra foi executada pelo maestro Ettore Bosio 17, também pianista e compositor, amigo de Meneleu desde os tempos deste como estudante em Milão.

15 A República (Belém), 18/06/1893, p. 1.

16 A República (Belém), 29/07/1893, p. 2.

17 Folha do Norte (Belém), 29/10/1896, p. 3. 


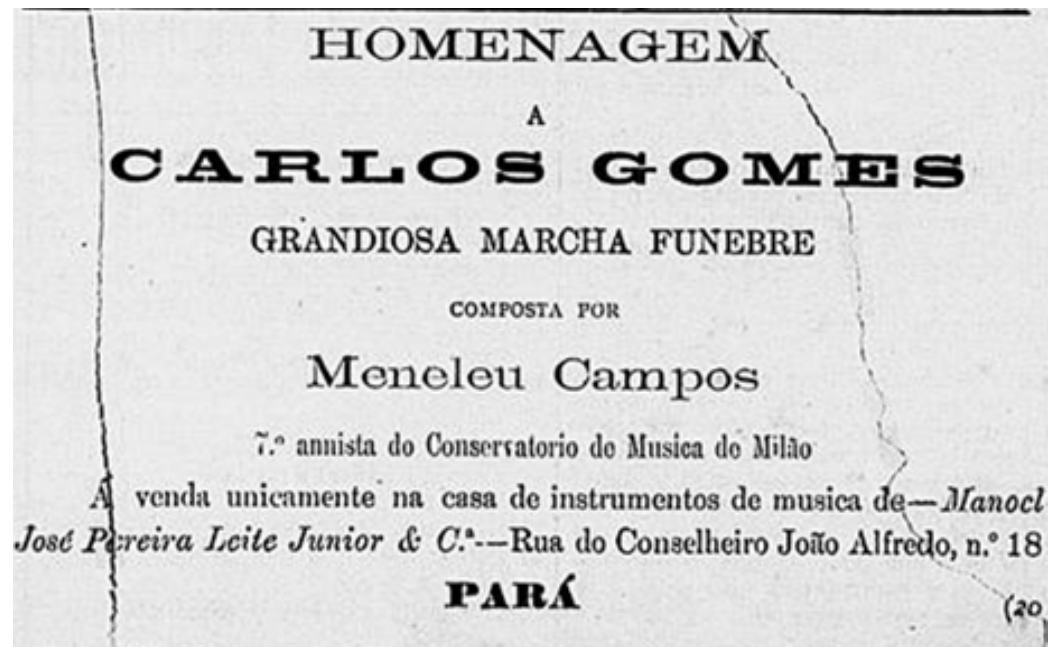

Folha do Norte (Belém), 01/11/1896, p. 4.

Segundo Márcio Pascoa, Meneleu e Bosio combinavam ainda posteriormente atuações conjuntas nos projetos de Belém:

Nessa altura, o Instituto Carlos Comes oferecia à cidade uma orquestra de concertos completa. Notar o grande número de músicos italianos ativos em Belém, remanescentes de antigas orquestras de companhias líricas. Meneleu Campos ausentou-se em 1903 para uma série de compromissos na Itália, assumindo a direção da orquestra o maestro Ettore Bosio que apresentou, no Teatro da Paz, uma série de concertos vocal-sinfônicos (apud PARACAMPO, 2018, p. 137).

curso de graduação de Meneleu durou ao todo oito anos, sendo concluído em 1899. Como era de se esperar, os jornais paraenses não pouparam elogios ao feito de seu compatriota, hoje considerado um desafio aos brasileiros, especialmente aos menos favorecidos. Ao concluir o curso em Milão, Meneleu foi elogiado pelos examinadores por 
conta de suas provas finais no Conservatório $e$, antes de retornar ao Brasil, compôs ainda o Quarteto em Lá maior apresentado nos salões da Famiglia Artistica (uma associação milanesa de artes e artistas, fundada em 1873), a 25 de novembro de 1899, com destaque na imprensa italiana (COSTA, 2011 , p. 42).

Segundo Vicente Salles,

pelo fato de suas obras possuírem frases claras, boa instrumentação e demonstrarem a capacidade do músico como compositor, os jornais italianos da época, Corriere della Sera, I Tempo e La Lombardia descreviam-nas como sendo elegantes, simples e geniais. No jornal La Perseveranza lia-se: "no trabalho de Campos se ouve a clareza e dignidade melódicas aliadas à pureza da forma" (apud COSTA, 2011, p. 42).

$\mathrm{Na}$ imprensa carioca lemos Meneleu Campos definido como sucessor de Antônio Carlos Comes. Com sabedoria, o jornalista define o compositor paraense em seu "posto eminente entre os nossos grandes artistas", e não apenas pela mera erudição - afinal, erudição é aquilo que se aprende na escola e depois se aplica, e sabemos que na arte há o desvelamento de uma linguagem por meio do mundo da obra que transcende e muito a tal erudição. A notícia dá conta da correspondência do cônsul brasileiro em Milão, Joaquim da Silva Lessa Paranhos, com o governador do Pará, José Paes de Carvalho: 
weseleu Campon - No horiconte da arto brasileirs surge um astro novo a irradiar esporangas de glorias para a sua patria.

Acaba de terminar seu curso no Conservatorio de Mililo o joven paraense Meneleu Campos, os triumphos por elle colhidos durante o curno denunciầ, mais de que um musies erudito, um compositor para quem o futuro reserva um posto eminente entre os nossos grandes aro tistas.

Damos em sezuida o officio em que o Consul brazileiro em Mlilĩo communies o facto as Governador do Estado do Pará, e a resposto deste:

* Consulado dos Estados Unidos do Brazil. Iitiåo, 11 de Julho de 1899 - Sr. Goveinador - Hoje tive a honra de pasoar á V. Ex. o seguinte telegramma :

aPaes Carva!ho - Governador - Para. Meneleu Campos diplomado. - Paranhos, Consul,. $\mathbf{O}$ que V. Ex. terí interpret vio :

« O Sr. Octavio Meneleu Campoz, Paraenses estudante de composição musical neate Coy se:vatorio de Mrusiea, superou brihafitemente todos os exames do ultimo curso e receb a o diploma que the confere o ti iulo de waestro-compositor. $\$$

Permitta-me, Sr. Governador, que por e to grato acontecimento apresente a V. Ex. e so nobre povo paraense, que tĩo larguesdis e g:nerosamente agasalhou o meu pranteado amis - maestro Carlos Gomes, as mishas sincoras felicitaçōes, augurando que o maestro paraense Meneleu Campos seja o succe-soremuio do grande maestro paulista, dando houra e gloria á sua terra nata! e ao nosso amado Braxil. 
Aoolha V. Ex. 03 protestos de minha elevada - respeitosa consideração.

Saude e fraternidale. - 0 Consul Joaquim de 8iles Lessa Paranhos. - Ao Exm. Sr. Dr. Paes de Carvalho, Governador do Eştado do Park. D

a Palscio do Governo do Estado do Pari. Belém, 8 de Agosto de 1899 - 12 Directoria - Sr. Con-ul - Tenho o prazer de accusar o recebimento de vosso officio de 11 do mex findo, em que confirmais o voaso telegramma da mesma data, cornmunicando-me haver o estadante paraense Ótavio Meneleu Campos recebido, no Coaservatorio de Musica deas cidade, o diploma de maestro-compositor.

Agradecendo-vos ns felicitą̧̄os que me dirigis pelo exito brilhante dos estudos desso distincto moego prraenso, apresento-vos as ex-

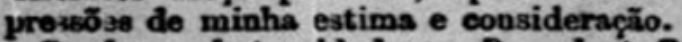

Saude fraternidade. - Dr. José Paes de Carvolho. - Ao Sr. Joaquím da Silva. Lesas Paranhos, Consul do Brazil em Millăo. "

Registrando um iscto ti็o auspicioso as futuro da arte musical brazileira, a Protincia do Pans de 17 de Julho findo esereve o seguinte art'go que pedimos permissão pars inserir nas noesas columnas :

- Agora, que, por despacho telegraphico, temos conhecimento de ter sido diplomado pelo Conservatorio de MIfilio o esperançoso maestro paraense. Menoleu Campos, parece-nos do toda opportunidade a publicagão de alguns trochos de uma carta, vinds houtem pelo Hilary. - escripta daquella cidade, por pessos que muito so intereass pelas cousas do Pard.

Delles verifiea que o resultado obtido pelo nosso conterraneo nito foi um facto trivial, e sim, pelas cireumstancias que o acompanhírão, utua verdadeira e explendida vi॰ ctoria. 


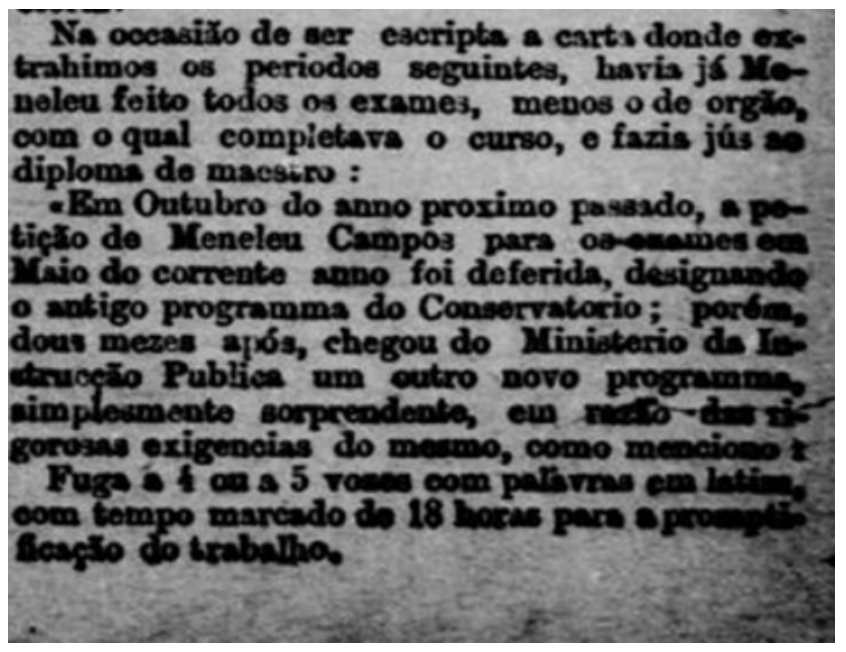

Jornal do Commercio (Rio de Janeiro), 1/9/1899, p. 4.

Vincenzo Cernicchiaro, em seu livro de 1926, já se referia a Meneleu Campos por conta de sua brilhante formação acadêmica em Milão:

Em 1898 [sic, o correto é 1899], completou os estudos musicais sob a orientação de Ferroni, professor de harmonia e contraponto no Conservatório Real daquela cidade. Nos exames finais, nos quais se saiu brilhantemente, por mérito nas disciplinas de composição, recebeu elogios especiais por parte dos examinadores, enquanto testemunho de particular consideração (CERNICCHIARO, 1926, p. 335).

Meneleu chegou ao Brasil a 10 de janeiro de 1900 (apud COSTA, 201 1, p. 42). Sua vinda foi repleta de regozijo e saudações na imprensa da capital paraense, como se lê abaixo: 


\section{MENELEU CAMPOS}

Xo sobidense acahou de chegar o nosso lanreado patricio, maestro Meneleu Campos, que no Soula, de Milaso, soulie honrar o nome paraetise. se revelando un substituto digno de nosso inolvidavel Cintos liomes, a naior gloria musial do lirazil, que pelo grande coratio foi parsense, vaule exhalon oultimo saspiro.

Sandames as novel manstm, feliritando g sr. Mariulo Cimpos e sua digana eyosa por tamandit aloriis.

A República (Belém), 12/01/1900, p. 2 


\section{Meneleu Campos}

$\longrightarrow$

Regressou hontem á terra querida que the fol berco e ao lar idolatrado da familia estremosa, o joven maestro paraense Meneleu Campos.

Ao seu desembarque concorreu grande numero de amigos e admiradores, slém da sus illustre familia. Seu velho pae lá estava, alma cheia d'essa santa alegria, que 6 um orgatho e que é uma veneraçăo, so estreitar nos braços o filho, que soube honrarthe 0 nome, honrando tambem a $\mathrm{Pa}$ tria, á qual regressa glorificado, possuidor de um titulo que o enobrece, conquistado pelo esforço e pelo talento.

Dando ao joven maeztro as mais sinceras boas vindas, sAo os nossos votos, intensaments patrioticos, que a terra que lhe foi berço, saibs acothel-o como merece.

A Meleneu Campos as nossas saudaçoes.

O Pará (Belém), 12/01/1900, p. 2.

A imprensa paraense considerava Meneleu Campos o substituto de Antônio Carlos Comes. Tamanho era o seu prestígio, rendendo-the o convite, no mesmo dia de sua chegada a Belém, para a direção do Instituto Carlos Comes, cargo assumido a 26 de janeiro $1900^{18}$.

18 Jornal $\bigcirc$ Pará (Belém), 28/02/1900, p. 1. 
No dia seguinte à sua chegada em Belém, Meneleu se associou ao Centro Artístico, instituição na qual manifestou desejo de ser membro ainda na Itália, tendo sido aceito pela unanimidade dos votos entre os associados. $^{19}$

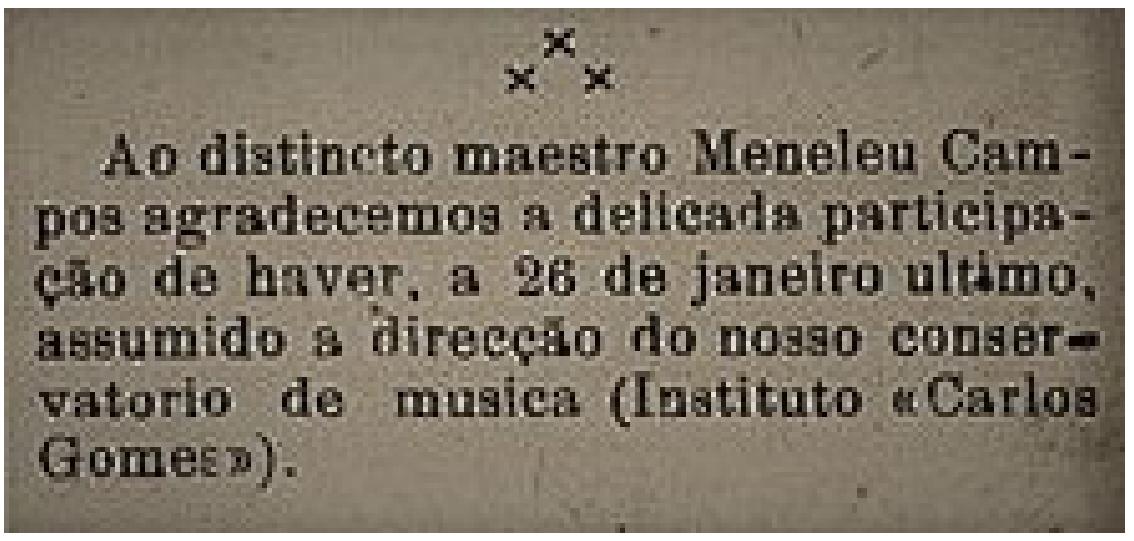

O Pará (Belém), 28/02/1900, p. 1.

Ainda em 1900, Meneleu Campos retornou à Itália, retirando o seu passaporte em outubro deste mesmo ano ${ }^{20}$. $\bigcirc$ motivo teria sido o seu primeiro casamento com a cantora Roseta Bossi, falecida em 1902, em decorrência de complicações na gravidez (COSTA, 201 1, p. 42).

De volta ao Brasil, em 1903, Meneleu Campos solicitou licença do Instituto Carlos Comes para retornar à Europa, onde se apresentou em concertos e publicou dois livros didáticos: Novo methodo de solfejo (1903) e Elementos de música (1904), ambos em Milão, pela editora de Romualdo Fantuzzi.

19 Jornal $\bigcirc$ Pará (Belém), 20/01/1900, p. 2.

20 A República (Belém), 30/10/1900, p. 2. 
Registo de Arte

M Emtono DE 80LTrso

o macstro Menelau Campos achs go em Milâo, onde acsba de editsr o seu ultimo trabalho - O Noco Methodo de Solvejo, com o quol tove em vista proporcionar aca slumnos de musica um processo mais aimples.o msis racionsl do aprendel-a em pouco tompo, resultádo de pesquizice o de experienciso do Inspirndo compositor.

0 trabslbo á precotido do uma missiva de Bttore Pozsolli, o celebre profesaor do theorin e rolfejo do tReal Conservatorio G. Verdí, de Milló, em a qual elfe declara. 80 s08so compatriots, entro outras cousas egusimente elogioasa:

¿Achei-o perfeitamento correaponJente so escopo preflixo. Observei $\operatorname{com}$ que criterio v, \&. dispoz na diffeuldades rytbenieas e melodicos a como todas a to coordenadas do maneira tảo progressiva que pedem fscilmente ser comprehondidso, mesmo pelos diacipulos os mais jovens.

Elogio'o, especialmente, pela ma neirs facil o racionol que v, a. expỗo no principio do ecu Metho do, 0 que serve para apreader com cerlezs e entosça to todos os intor vallor malodicos o chromaticos,?

o trabslbo de Meneleu Compos, diz o Jornal do Commercio, émsia um documento de sus competencia techuica o da sua imaginativa cres. dero. An melodias quo constituem ss liceves graduees. dos ns, 1 a 160 , Róo inteirsmento deliesdsa e intei Wmento novas: o gradocto do mais sintelea para o maia dilßcil es de uma nsturafidade perfeita : os mil proble rise da eacripto, do notapiro musical, do agrupamento e varia ça dos vislores, tudo 1930 que laz. a sciencia tso lacil o diritleil da musiea bseripta, esta disposto o si. tuada cada cousa a seu tempo e sm seu lorar, no Nobo Methoilo de Meacleu Campos, hums clareza o cropriedado quo juatini eam a ple situde, a apreciagdo do professor Poxzoli. 


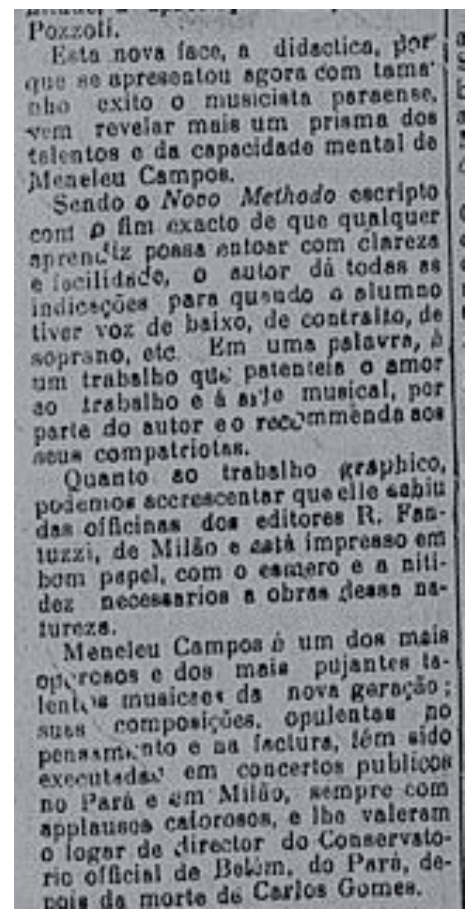

Correio Paulistano (São Paulo) 22/02/1904, p. 2

Em 1904, retomou suas atividades no Instituto Carlos Comes, permanecendo no cargo até 1906. Neste mesmo ano, Meneleu se casou pela segunda vez, "com a violinista e pianista Marieta Guedes da Costa" (op. cit., p. 44), com quem teve sua primeira e única filha, Sulamitha da Costa Campos. 


\section{Varlina}

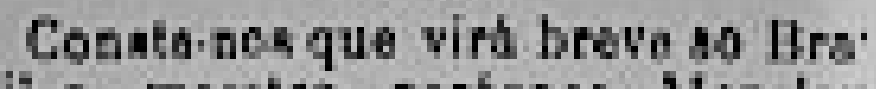
dil 0 matatro porhnas Menuleu

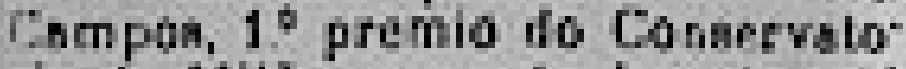
- lo do MHISo, qud actosimen le eah dhndo coneertos symphonicon ns" qualla coptel e refebando arngen inerecida no onu brilbsala halenbo artiatico

Wencled Campos loi quen nub.

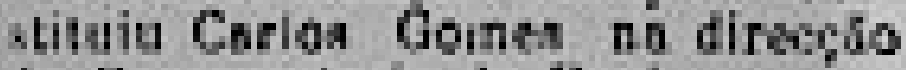
do Gonerralorio do Pard.

Correio Paulistano (São Paulo), 15/0 1/1904, p. 2

Segundo Cernicchiaro, "em 1904, Meneleu Campos pretendia apresentar, em Milão, uma ópera melodramática Gli eroi, sobre libreto de llica, mas parece que não conseguiu fazer com que desse certo" (CERNICCHIARO, 1926, p. 336). Lembramos que Luigi lllica (Castell'Arquato, 1857-1919) foi libretista e autor italiano de comédias, dos mais famosos em seu tempo - autor, entre outras, de libretos de óperas célebres, tais como Manon Lescaut (em parceria com outros libretistas), La Boèhme, Tosca e Madama Butterfly, do compositor Giacomo Puccini.

Por sua vez, segundo Janu Parente, Meleneu Campos regressou à Itália em 1907, onde concluiu a ópera Cli eroi e tentou incluí-la, sem sucesso, na temporada de óperas em Milão. Tão pouco obteve êxito na programação de sua ópera em Paris. Retornou ao Brasil no ano seguinte (apud COSTA, 2011, p. 44). 
Já Márcio Páscoa e Rossini da Silva informam que, por volta de 1902, em contato direto com Luigi lllica, "Meneleu recebe das mãos deste autor referencial do Naturalismo o libreto de Cli erol" (PÁSCOA; SILVA, 2008, p. 2).

Contudo, ainda há muito para se esclarecer sobre o processo inventivo desta ópera. Os próximos passos de pesquisa deveriam ser a localização precisa de uma possivel partitura (grade) da ópera (e não apenas versöes para piano), esclarecer melhor as relaçöes de Meneleu com lllica, como se deu de fato o contato ou a possivel amizade entre eles, se Meneleu adaptou libreto já existente ou se Cli eroi foi um libreto original de llica escrito especialmente para Meneleu. Outra questão é, por que o título não consta do catálogo de libretos de llilica? Há notícias brasileiras sobre o projeto, mas quase nada em fontes italianas ou atreladas aos estudos sobre llica.

Logo abaixo, reproduzimos a notícia da "Opera brasileira", chamada "Heróes", onde se relata o encontro "em almoço íntimo" em Paris, a 13 de dezembro de 1906, de Meneleu com Illica, estando presente também ninguém menos que o próprio Puccini, incluindo as esposas dos três artistas. $\bigcirc$ compositor mostrou os atos prontos da ópera ao libretista, cuja recepção teria sido de "enthusiastica satisfação". Já segundo Puccini, a ópera Cli eroi "Ihe pareceu destinada a um real successo". A fonte destas raras informações foi o literato paraense João Marques de Carvalho (Belém, 1899, Nice, 1910): 


\section{Opera brasileira}

A Provincia do Pará que se pu. blica em Belém assim se refere ao compositor brasileiro Meneleu de Campos, autor da opera Heróes que se vae montar em Milăo :

Achava-se em plena actividade em Paris o nosso collaborador artistico maestro Meneleu Campos.

A 9 de dezembro ultimo chegara áquella capital o illustre poeta libreiista Luigi Illiea, afim de conforenciar com Meneleu Campos sobre a sua opera em andamento e ouvirIhe os actos ja terminados.

Nosso companheiro Marques de Carvalho teve ensejo de conversar com Luigi Illica sobre aquelle trabalho do compositor paraense e com especial agrado verificou a enthusiastica satisfaç̃̃o do libretista.

Ou eu não enterdo mais de libretteis, nein de musica, nem de publico, ou Qli Eroi ( $O_{3}$ Heróes), titulo da opera, vae ter um grandissimo exito ein Mílão, no anno proximo, quando fòr representada."

Esta opinitio corresponde a um augurio de valor, pois Luigi Illiea 6 - libretista feliz de Puecini, Mascagni, Franchetti e outros jovens já celebres maestros italianos.

No dia 13 de dezembro encontra* ram-so em almoco intimo, em um dos mais bellos salúes do Restaurante Italiano, o celebre autor da Boheme e Manon, Giacomo Puceini, que está em Pariz assistindo os ensaios da san opera Madame Butterfly, na Opera-Comica; o libretista Luigi Illica; o maestro Menedeu Campos; as esposas destes tres artistas e o nos. so confrade Marques de Carvalho. Foi uma refeicito encantadora para o director d'A Provincia do Parć, pois tanto a Puccini como a Illica teve ensojo de ouvir mui lisongeiras referencias ao Brasil, Puceini e a esposa estiveram, ha pouco, algumas horas na bahia do Río de Janeiro, em transito de Buenos Aires para a Europa e ficaram fascinados pelas incontaveis belezas naturaes que formam o quadro da nossa vasta capital Federal. Refeição absolutamente intima, em que nũo se fallou señ̃o da arte, sem preoccupaçōes de estylo, esse almoço fol rematado por uma saudaçio conjunta ao exito de $M$ a dame Butterfly em Pariz, gontileza a quo Puccini correspondeu com um brinde cordialissimo ao seu joven confrade Mencleu Campos, cuja opera the pareco cdestinada a um real suceesso,

Jornal A Federação (Porto Alegre), 15/02/1907. p. I.

\section{3}

REV. TULHA, RIBEIRÃO PRETO, v. 7, n. I pp. 131-175, jan.-jun. 2021 
Henelua Cumpon e Xist-al 11.

Itea -0 illestro pucta flaliano, Lubigi IIIlea, aselor to taatios Ithretus tamosus, arabs do passar, coin sita encinladora es. pos, alguns ditis eall Paris, a couvito ur nos:0 distinclo compitriuta, o maestro Stenielen rampjos.

Coms ha tempos tivo ocesstín de noticiaz aos Icllures da Gazla, o puela eo coisposilor tratiallasn nutma nova opera bli Broi, que denlro de uin anno será reprosenlada no theatio Srala, to Milño. Gili Brod compóc-se do 4 aelos de musica magniflea, se so quiz or dar cridito aos raros pirivileghados que ourlram alguns Irechos da parlitura.

Nosso compratriola a seu llitstire collahoridoé aeaham de partif para a llalia, on te o maestea Campos sers, ear Chastella. quarto, hospoce do foeta, que allf posstae una magnified propriedade, $W$ nessa visirnda yes os dods arthlas contam dar a sua obra os altimas rotojutes, antes te apn-s.atal-a ja-putijoo.

va vespera da partida, n anastro Canpas manilu, ean torio da ahss de una 


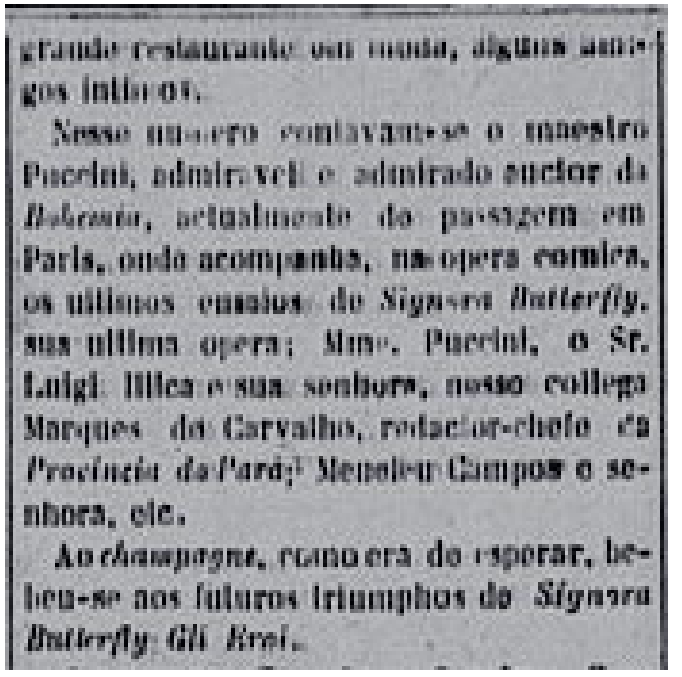

Gazeta de Notícias (Rio de Janeiro), 2 1/1/1907, p. 2.

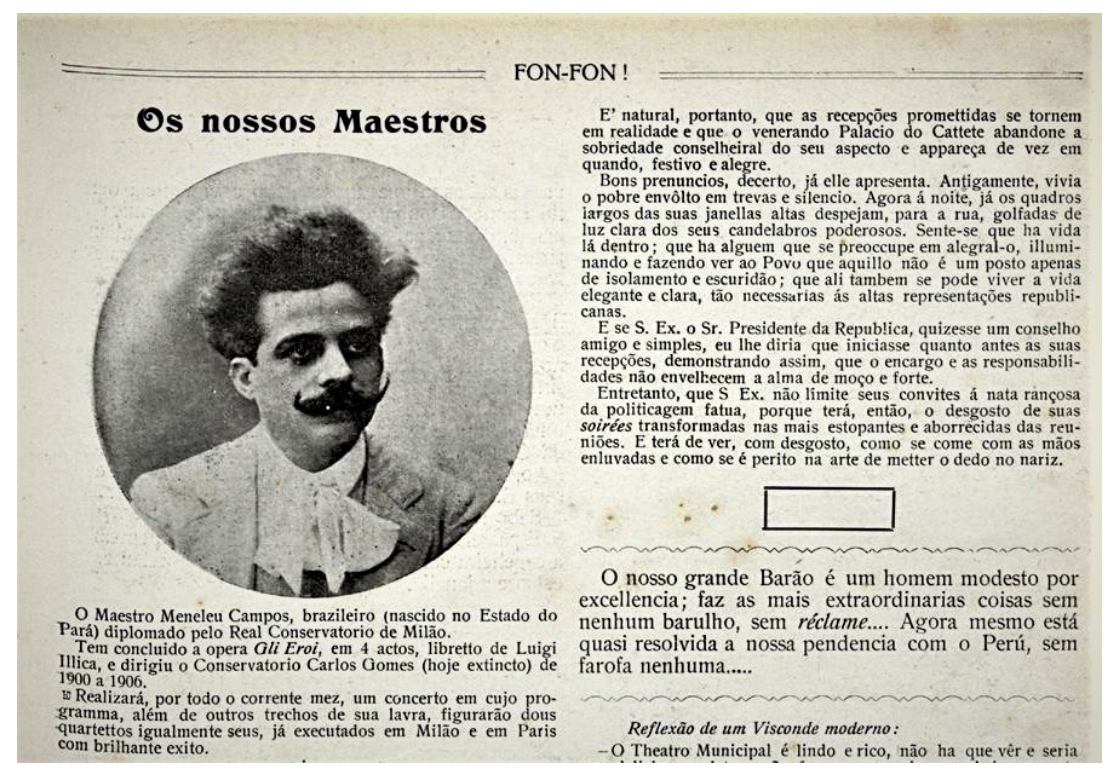

Revista Fon Fon (Rio de janeiro), 24/07/1909, Ano 3, nº 30, p. 23. 


\section{Maestro Meneleu de Campos}

l.a Gassife du Brisit vublicon, em yus elichio de 31 de turco, tima nota testacada $n$ a um terapo carinhosa justa, relerente so trespasae, ececrrido ba putoo - do illuxtre connosițor brasileifo marstro Meicles de Caminos. A sua Nymachlo atistiva, foe era fas mais invejaveis, oa seas perdores que, en ple. no amanhecer da vida, se revelaram es cstalos, que fez no Conservatorio Real de Mi'go, e eas seguida a sua designaço pa. ra dirigir o Coeservatorio do Delétn do Pará, suecederabo eo glorioeso compositot Carivs Gounes: os concertos realirodos nas principaes capitaes e cilades da Eis. ropa - tubo isso vens fielnente narra. to ta bern feita local da Casctic du Bre. sil - não se falando em episodios ou. tros muitos e multiplos da vida ghoricea do eaninente coragrositor.

Medielen Campos foi, realnente, em toda a sun carreina artistics uma figura de cicicio. Foi o Sr. Pates de Carvalbo, ao tempo sovernador do Pará, que des: ignou o crande muxico para dirigir o Conservatorio de Beién. Durante oito onnos, coan aturado cariubo, consagrou sua intelligencia a essa instituiça gue, sob o influxo da sua forte voatade, oc tornos um dos mais notaveis do ensino superior da musica no Brasil. Era, porém tal a irrudiaçio do seu taiento que crit 1900 e 1905 foi chamado á Euroga para dar concertas oas eapitacs mais adiantados.

A esse tempo, apresentora aos maextros muitas, numerosas de suas couposigites, aue foram acolbiulas com grande carinho. Escas coepposiçbes, dilo a Gasefte du Brésil cerfaincmest, surtitront très longlemps d loair autcur,"

Meneleu de Campos compoz a magistral partitura Gli Eroi; infelizmente, poretm, e mercé de fáta de recursos, essa obra nio fol $\dot{a}$ scena.

Na culla capital do Pard, o esckrecido compositor promoves um movimento intenso em prol da cultura artistiea masical, quer atraves das suas preleccóea quer atruvés das avdicóes, com plese apoio do governo do grande Estado.

O Paiz (Rio de Janeiro), 02 e 03/07//927, p. 4.

\section{6}

REV. TULHA, RIBEIRÃO PRETO, v. 7, n. I pp. 131-175, jan.-jun. 2021 
O jornal Pacotinha, de São Luís do Maranhão, a 11 de maio de 1908, noticiou que Meleneu Campos pretendia fundar um "instituto de música" particular em Belém, tendo, inclusive, realizado alguns exames com "musicistas belemenses". Segundo Vicente Salles, seu instituto oferecia cursos de instrumentos de cordas, madeiras e metais, bem como solfejo, piano, canto, harmonia, fuga e composição (apud COSTA, 201 1, p. 45). Esta nova tentativa de empreendimento, por parte de Meneleu, também não satisfez às suas expectativas, optando por buscar melhor sorte no Rio de Janeiro, a partir de 1909. Sua recepção pela imprensa carioca foi positiva, rendendo-lhe elogios no Jornal do Commercio:

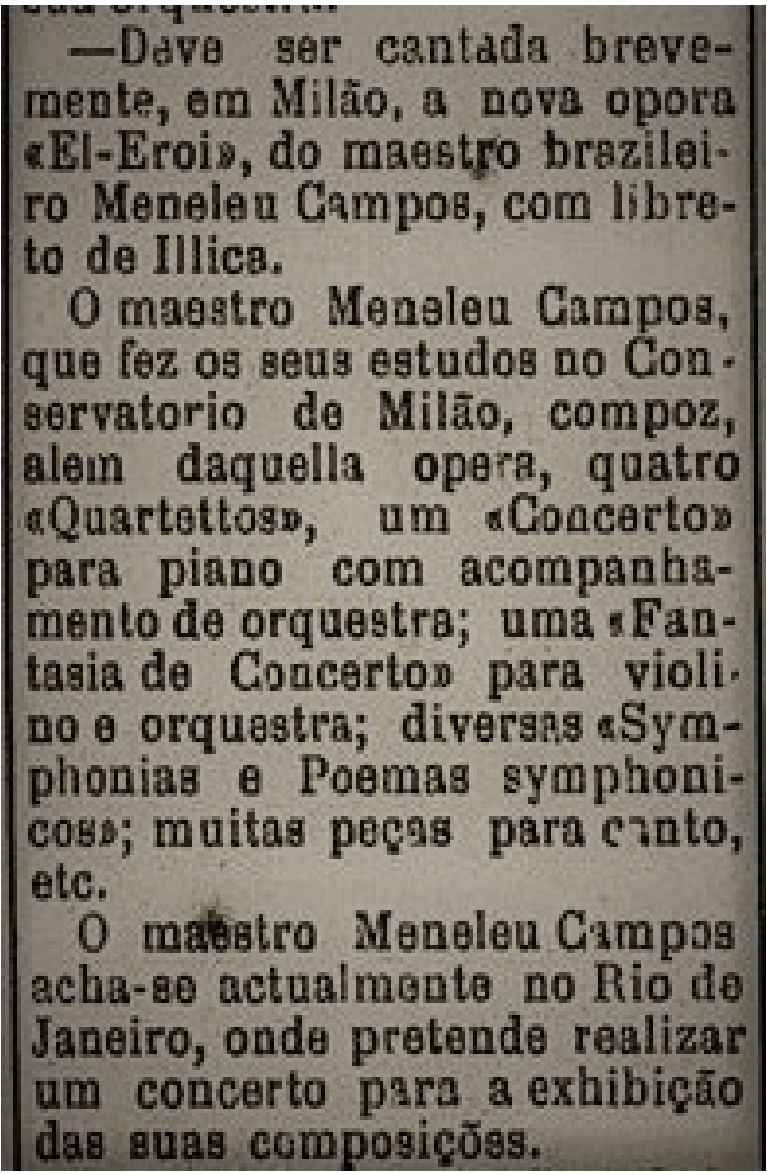

Pacotilha (São Luís do Maranhão), 0 1/09/1909, p. 1. 
Sua primeira apresentação no Rio de Janeiro ocorreu a 2 de agosto de 1909, no Salão da Associação Comercial, apresentando-se como "brasileiro laureado pelo Conservatório de Milão". ${ }^{21}$ Conforme se noticiou na imprensa carioca, o então presidente da república, Nilo Peçanha, fez-se representar no concerto de Meneleu pelo capitão de corveta, Jose Maria Penido. ${ }^{22}$

\section{Mrenelen Campos.}

E' este o programuns do concerto que depois de amanhá realiza to salso da Associaçio dos Empregados do Commercio, com a presenpa do Sr. presidente da Republica, o nuestro Menelet Campos:

in parte-Mcneleu Carspos-Quarteto para arcos (em ré maior), andante un po mosso, internezzo, echerzo e finale: Meneleu eampos, Notella del marc, romanza para soprano, corr acompanhacaiento de pequena orchestra, pela Exma. Sra. D. Hortencia Cardinali; Meneleu Campos, It tento dolla tompcste, romanza para tenor, con scompanhamento de pequena orchestra, pelo comatendador F. Cardinali.

2* parte-Mencleu Campos-Quarteto para arcos. (em nit maior), andante sostenuto, minuteto, schorzo e finale; Meneleu Campos, Cielo e mare, romanza para soprano, com acompanhameuto de peruena orchestra, pela Exma. Sra. D. Hortencia Cardinali; Mencleu Cansgos, Primavera, romanza para tenor, com acounsatsamento de pequena orehostra pelo combiendador F. Cardinali.

Os numeros de canto serío regidos pelo autor,

$O$ coscerto começari ás 9 thoras da noite.

O Paiz (Rio de Janeiro), 31/07/1909, p. 4.

$21 \bigcirc$ Paiz (Rio de Janeiro), 21/07/1909, p. 2.

$22 \bigcirc$ Paiz (Rio de Janeiro), 03/08/1919, p. 1. 
Após este concerto, Meneleu visitou o Palácio do Catete, em agradecimento ao presidente da República, conforme se noticiou a época.

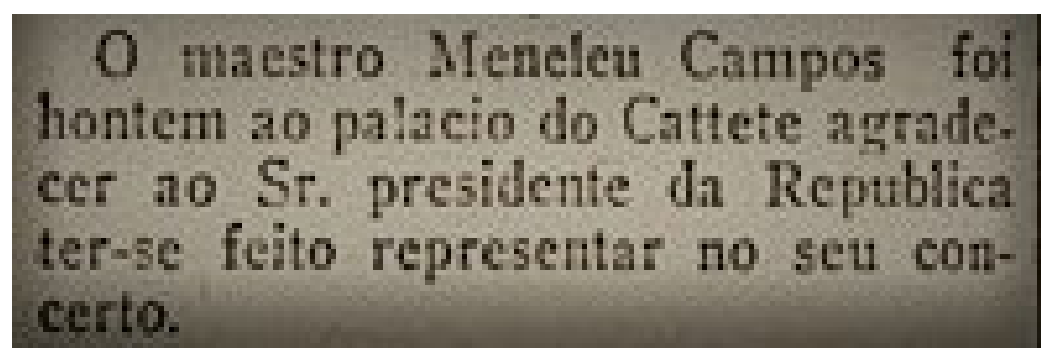

O Paiz (Rio de Janeiro), 08/08/1909, p. 2.

Quanto à sua estada no Rio de Janeiro, em julho de 1909, Cernicchiaro (1926, p. 336) dá notícia de Meneleu ter apresentado ali seus dois últimos quartetos, executados por importantes músicos da época, tais como Jeronymo Silva ( $1^{\circ}$ violino, aluno de Cernicchiaro, recebeu a medalha de ouro do Conservatório Imperial, hoje EM-UFRJ, em 1888), Vincenzo Cernicchiaro ( $2^{\circ}$ violino, professor do Imperial Conservatório de Música, depois Instituto Nacional de Música, dos mais importantes cronistas da música brasileira), Ernesto Ronchini (viola, também compositor, professor e posteriormente maestro da orquestra de alunos do Instituto Nacional de Música, hoje EM-UFRJ) e Rubens Tavares (violoncelo, dos maiores solistas do Rio de Janeiro em seu tempo) - um dos poucos registros sobre a possível execução dessas obras.

De volta à Belém, Meneleu tentou reorganizar o seu instituto de música, mas a cabou encerrando suas atividades em 1912, quando decidiu realizar mais uma viagem à Europa. Segundo Costa (201 l, p. 46), esta viagem, que se iniciou em 1913, foi motivada em razão do tratamento de saúde de sua filha. Após uma curta passagem por Paris, 
Meneleu foi a Lisboa, onde permaneceu por dois anos e, por este tempo, chegou a fundar "uma escola de composição e harmonia" (Ibidem). Retornou com a família ao Brasil, em 1919, quando tentou reativar o seu instituto de música em Belém e fundou o Orpheon Meneleu Campos. Também assumiu, nesta mesma época, o "Serviço de Canto Coral do Estado", fundou o grupo de câmara Septuor e ocupou o cargo de presidente do "Centro Musical Paraense" (Ibidem).

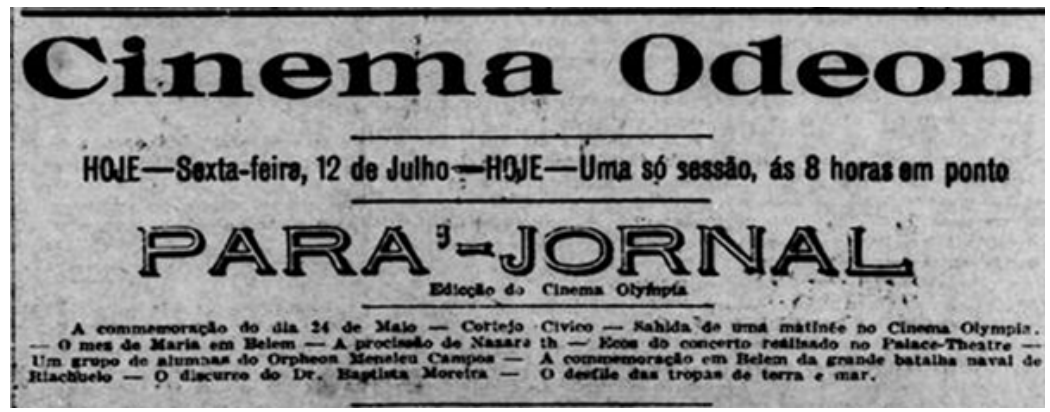

Jornal do Commércio (Manaus), 11/07/1918, p. 4.

Entre 1916 e 1926, Meneleu Campos permanecev em Belém, onde promoveu concertos sinfônicos e vocais, atuando também no ensino musical da capital. Em dezembro de 1926, decidiu viajar a Niterói, onde sofreu um infarto fulminante, vindo a falecer a 20 de março de 1927 , então com 55 anos de idade (COSTA, 2011, p. 47). Foi sepultado no Cemitério Maruí, em Niterói. ${ }^{23}$

Além dos quartetos, Meneleu Campos é autor de mais de 100 obras, ainda injustamente esquecidas em arquivos brasileiros. Há notícias de óperas, tais como II Salvocondutto (1899) e Cli eroi ( 1904 1907), de outras composições sinfônicas, Prelúdio em Ré maior (1893),

$23 \bigcirc$ Paiz (Rio de Janeiro), 21 e 22/03/1927, p. I. 
Tango (1897), Sinfonia em Lá maior (1898), Suite brasileira (190 1), Marcha nupcial (1902), demais instrumentais Adorée (1915), Grafira (1888), Pétalas esparsas (1888), Miniatura (1898), Tendrement (1913) e Snowflakes ( 1921 ) e vocais, como O Baile na flor (1 899), Canto noturno (1899), Perchè (1901), Nella mia barca (1901), Romanzetta (1903), Hinos das normalistas (1903), Alla Mamma! (1908), Infiniment (1913) e Marcha infantil (1925), entre outras obras.

\section{Quartetos de cordas}

Não obstante Meneuleu Campos ter sido o Patrono da Cadeira n 35, quando da fundação da Academia Brasileira de Música, no Rio de Janeiro, em 1945, sua obra não tem sido divulgada pelas principais instituições musicais no Brasil. Seus repertórios contemplam composições próprias, arranjos e adaptações, abrangendo obras sinfônicas, operísticas e camerísticas. Além de seu bom número de obras musicais, e das suas citadas obras didáticas, sua recepção artística talvez tenha sido prejudicada por conta de seus caminhos poético-estilísticos. Apesar de terem sido elogiados por músicos, críticos e público na época, os quartetos de Meneleu Campos, por exemplo, não lograram um pertencimento efetivo aos programas dos quartetos brasileiros enquanto ensembles musicais - acrescente-se a isso que boa parte da música de câmara brasileira do século IX e início do século XX ficou também esquecida.

Claudio Cruz, anteriormente frente ao Quarteto Amazônia e agora frente ao Quarteto Carlos Comes, vem procurando reconstituir a memória dos quartetos de cordas da geração romântica, de compositores como Antônio Carlos Gomes, Santana Gomes, Alexandre Levy, Glauco Velasquez e Alberto Nepomuceno, entre outros. A edição crítica de suas solfas e a gravação de CDs, todos inéditos, da integral dos quartetos de Meneleu, procuram preencher parte desta lacuna na 
práxis (interpretação-execução) da história musical brasileira. Ainda são raros, portanto, os estudos sobre Meneleu e a programação de sua obra nos teatros brasileiros.

Contudo, segundo Rubens Russomanno Ricciardi,

a poética (ou poíesis, a elaboração inventiva de obras de linguagem) dos quartetos de Meneleu Campos apresenta um artesanato altamente refinado quanto ao tratamento do material musical. $\bigcirc$ amplo domínio harmônicocontrapontístico e o equilíbrio textural possibilitam ao compositor paraense o desenvolvimento de melodias inspiradas e demais motivos e ideias musicais sempre de rara beleza (RICCIARDI, 2021 ).

Por que, então, a recepção da obra de Meneleu tem sido tão prejudicada? Uma hipótese de trabalho, levantada por Ricciardi em sua disciplina de pós-graduação pela EACH-USP, talvez possa ser cogitada neste contexto: o Positivismo, influente no Brasil desde o golpe militar que instaurou a Velha República, em 1889, acabou impregnando toda uma conotação excludente modernista, com o lema "abaixo as velhas taperas", em nome da "ordem e progresso", para que todo o passado artístico do Brasil, desde os primórdios da colonização, fosse literalmente "posto abaixo". Como resultado deste positivismo políticocultural devastador, temos não apenas a destruição do arquivo da Real Câmara e Capela, cuja história no Rio de Janeiro remontava a João $\mathrm{VI}$, e demais arquivos de música colonial, como também a demolição sistemática dos centros históricos das principais vilas e cidades brasileiras, tornando-se, por fim, referencial também à geração de 1922. Os positivistas queriam destruir tudo que lembrasse Portugal, Clero e Monarquia. E nada há de mais positivista que a seita do progresso em Oswald de Andrade. É um tipo de ódio no qual se joga o bebê junto com a água suja do banho. Junto com símbolos portugueses, clericais e monárquicos, toda arte produzida no Brasil, desde o descobrimento, 
acabou por ter deteriorada sua apreciação - Anchieta, Vieira, Lereno, José Maurício, Aleijadinho e Carlos Comes, e todos os demais artistas brasileiros, foram sumariamente menosprezados. Soma-se a isso uma leitura redutiva do Ensaio sobre música brasileira (1928), de Mário de Andrade, a partir do qual não se valorizou, ao longo de gerações, os repertórios musicais brasileiros que não levassem em consideração a incorporação, na música escrita, de sonoridades populares urbanas e rurais, ditas folclóricas. É o caso de Meneleu, o qual não se aproximou de cantos ou danças populares, elaborando uma poética musical contextualizada no século XIX, mas cuja abstração formal lembra mais os estilos composicionais de Camile Saint-Säens, Charles Counod, Jules Massenet, Glauco Velasquez, Henrique Oswald, Francisco Braga e Leopoldo Miguez, entre outros.

Não percebendo a irreverencia destrutiva de Oswald de Andrade - incluindo o discurso igualmente truculento de Graça Aranha -, toda uma parte dos estudos culturais no Brasil, ao longo do século $X X$, confundindo estética com poética, compreendeu os manifestos Pau Brasil (1924) e Antropofágico (1928) enquanto estética e teoria da arte, e não como de fato foram, manifestos poéticos, com os quais os artistas modernistas defendiam seus estilos e visavam a propaganda e agitação polêmica. A provocação irreverente, e não raramente leviana, virou filosofia crítica. Qualquer disparate poderia chamar a atenção para que a Semana de 22 fosse promovida: tudo que fora produzido até então deveria ser jogado no lixo - a mesma lógica com a qual nosso passado colonial arquitetônico também veio abaixo. Nas gerações imediatamente seguintes, os gurus modernistas continuaram a depreciar toda arte que não envolvesse elementos populares brasileiros.

Já nas gerações dos manifestos Música viva (1948) e Música nova (1963), na área da música, os compositores atrelados aos estilos composicionais do século XIX continuaram esquecidos e mesmo rejeitados, mesmo quando já havia sido superado o debate em torno 
da necessidade das sonoridades populares ou folclóricas na música escrita. Assim, por serem não apenas românticos tonais contextualizados no século XIX, como também por não trabalharem diretamente com sonoridades oriundas da música popular brasileira, compositores como Meneleu, Clauco Velasquez e Henrique Oswald, entre outros, tiveram prejudicada sua recepção posterior. Portanto, um compositor romântico tardio tonal e desprovido de temas folcloristas em sua obra, Meneleu caiu no esquecimento. 


\section{MENELEU CAIIPOS}

A' proposito do concertu de despe. dida dado pelo nosso laureado coestadano maestro Meneleu Camposá « Cramilia Artistica de Miläo, assim se expressaram varios jornaes ita. lianos :

Rsereve La Lombardia.

¿ O quartetto em 'lá maior do ma. estro Campos, director do conservatorio de Belém, onde suceede ao pranteado Gomes é um trabalho juvenil, de inspiraçáo fresca, concebido com ousadia $e$, so mésmo tempo, tevido com elegancia e simplicidade.

Todos os quatro tempos foram applaudidos, $\theta$ o publico saudou tambem pessosimente o auctor, que dá de sì boas esperanças.

$O$ quartetto em sol maior do man estro Ferroni, (professor de Meneleu), que rege a cadeira da aita composiça do nosso conservatorio, confirma a fsma de optimo musicista, de que gosa o autor de Rudello e Fieramasca.

Bita composiçăo, classificada em primeiro logar e premisaa em um concurso belga, é um trecho de musica concer tante verdadeiramente notavel pela quadratura, idéa e desen. volvimentos.

Diz La Perseveranza :

As peças mais salientes do programma foram dois quartettos para areos dos maestros Campos e Ferroni o primeiro diecipulo do segundo.

No trabalho de Campos sente-se a cisreza e dignidade melodica slliadas á pureza da forma: no de Ferroni nots.se a arte magistral do contrapon. tista, a largueza do desenvolvimento e a nutrida polyphonia, que captara o pleno suffragio d'aqueile numeroso publico de competentess.

Noticia L'Osservatore Cattolico:

A sociedade Famiglia Artistica insugurou hontem, com felicidade, os seus novos salóes por meio de um importante concerto musieal.

Do quartetto formado pelos professores srs. Segré (primeiro violino) Vajani (s gundo violino) Rossi (viola) e Galieszzi (violoncello), foi executado com correç̧a um quartetto em lá maior, do maestro Campos, no qual a inspiraçato se une a uma bôs technica.

Dos 4 tempos preferimos os dois primeiros, Allegretto e Alla Minuetto.

Do maestro Ferroni executou-se um quartetto em sol maior, que fo premiado em um concurso de Bruxellas, e que se impõe, com effeito tanto pela elegancia e elevação da concepção,como pela exquisita factur artisticas.

\section{5}

REV. TULHA, RIBEIRÃO PRETO, v. 7, n. I pp. 131-175, jan.-jun. 2021 
E' um trabaho que muito honre a Eerronis.

Refere $n$ Commercio:

*A Famiglia Artistica insugurou hontem á noite os seu vastos salóes

da rua $S$. Paulo n. 10 , com um concerto musical.

Executou-se um quartetto para arcos do joven maestro Meneleu Campos, um brasileiro, discipulo de Ferronis.

E' trabalho feito com muita alma, estimavel pela clareza do pensamento como pela naturalidade do desenvol. vimento, qualidades que tambem notamos no Canto Notturno (rom $35 z a$ ) do mesmo suctor, eantado pela Signorina Gambini, joven dotada de uma voz bella e dulcissima, a qual executou tambem outra rom nza Nevi. cando, felieisaima compos' cāo do ma* estro Ferroni, o terceiro fragmento da Biondina de Gounod e Marguerita au rouet, de Schubet

Acompanhava ao piano o projessor Pozzoli, de euto auctor cantou C'est toi que j'aime, outra romanz 3 deliv eada e bem feitas.

Ao Corriere della Sera, pertencem as seguintes palavrae:

๔Huntem á.noite tivemos um concerto na Famiglia Artistica e nelle ouvimos dois novos quartettos, sendo um do professor Ferroni e outro do Maestro Campos, ambos interessantes, o primeiro pela sulida conssrucçáo e o seguado pela genialidade.

Foram cantadas tambem pela $\mathrm{Si}$ gnorina Gamburi algumas romanzas de apurado gosto e da parte instru mental encarregaram se os ars. Pozolli, Segré, Vajani, Rosii e Galeazzis.

Anteriormente a este concerto isto é, d́ 17 de novembro, dera Me neleu Campos um outro concerto tambem calorosamente applsudido, que foi por ellé offerecido em homenagem $\hat{s}$ distincta familia Turri, ali residente.

O programma deste concerto, orga nizada unicamente de composiçōe do nosso joven maestro, foi o se guinte:

1.A PARTB.-M. Campos - Quartetto La magg - Allegretto-Alla miauetto -Scherzzo-Brioso ; Primsvera (ro manza) Tenore S:g Úmbert Frances coni;-Segreto in piazza (romsnza) Tenore Sig Umberto Francesconi.

2 * ParTB $-M$. Campos Dormi. dormi (cantilens arabe); Ba:so Si Giovanni Tansini-Cielo e Mare (ro manza)-Tenore-Sig. Umberto Fran cesconi:-in jondo al bicchiere (brin disi) -Tenore Sig Umberto France coni; Quartetto in sol magg. - All nou troppo - Adagio - ScherzoAllo. :

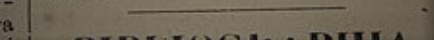

Para (Belém), 14/02/1900, p. 1.

\section{6}

REV. TULHA, RIBEIRÃO PRETO, v. 7, n. I pp. 131 - 175, jan.-jun. 2021 


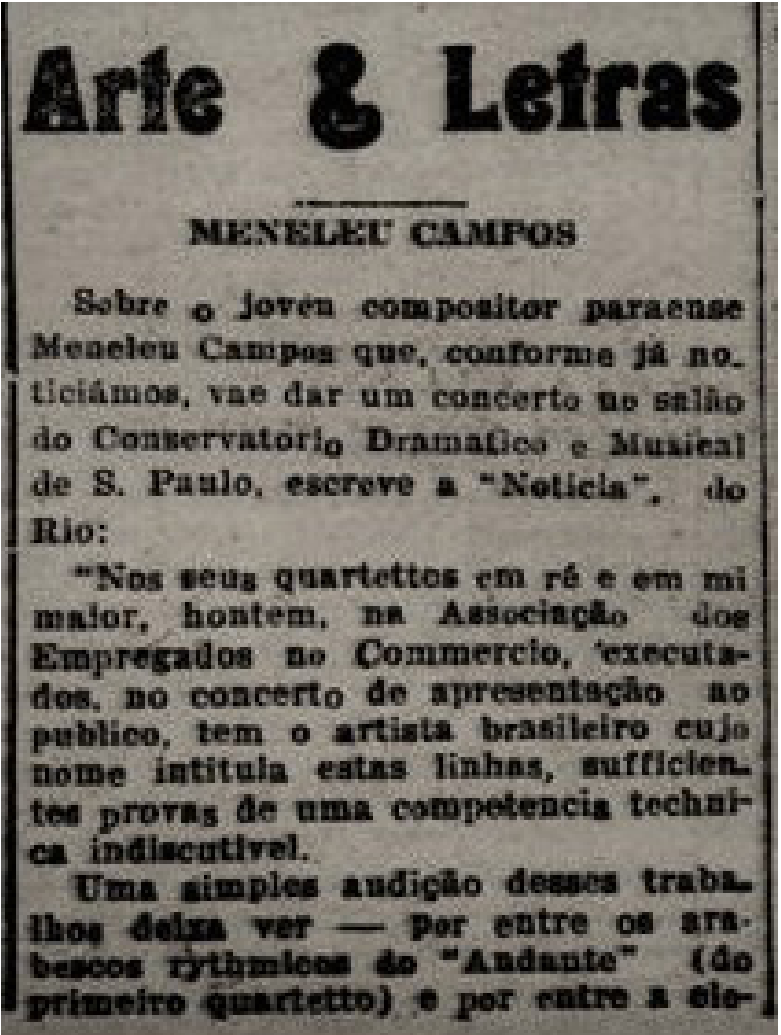




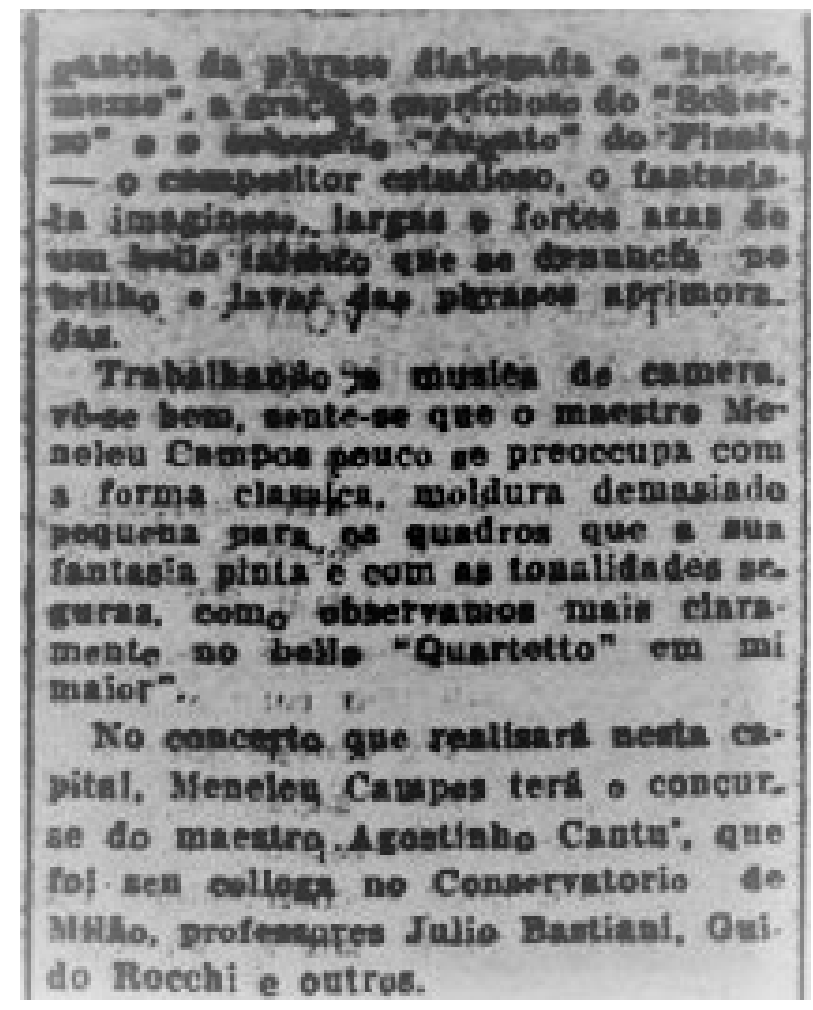

O Commercio de São Paulo, 06/12/1909, p. 2.

Sobre os quatro quartetos de cordas de Meneleu Campos, lembramos que foram compostos sempre em quatro movimentos, seguindo modelo do gênero que remonta ao século XVIII:

- Quarteto no 1 em Sol maior, composto em Milão, em 1899, com os movimentos: Allegro Molto, Adagio-andante, Scherzo-allegro e Finale-allegro;

- Quarteto no 2 em Lá maior, composto em Milão, em 1899, com os movimentos Andante un po mosso, Adagio ala minueto, Scherzo-allegro mosso e Finale-andante mosso; 
- Quarteto no 3 em Ré maior, composto em Belém, em 1901, com os movimentos Andante un po mosso, Intermezzo-largo, Scherzo-allegro e Finale-allegro spiritoso;

- Quarteto $n^{10} 4$ em Mi maior, composto em Belém, entre 1901 e 1902, com os movimentos Andante sostenuto-allegro moderato, Minuetto, Scherzo-allegro e Finale-allegro non tropo.

Anteriormente às gravações do Quarteto Carlos Comes, pelo Selo SESC, contudo, os quartetos de Meneleu Campos ainda não haviam sido gravados. Não obstante, desde pelo menos Cernicchiaro (1926, p. 336), lemos críticas favoráveis ao talento de Meneleu, por sua "competência singular". Seus quartetos primeiro e segundo, compostos na Itália, contemplam ainda um "excelente desenvolvimento de ideias, de ritmos e de concepções bem sucedidas", segundo Cernicchiaro (ibidem) - lembrando este violinista italiano, radicado no Rio de Janeiro, destacado estudioso da música brasileira em seu tempo, não apenas conheceu Meneleu pessoalmente, como foi ainda intérprete-excutor de sua obra. Portanto, falava com conhecimento de causa.

Os quartetos em Sol maior e Lá maior têm estruturas clássicas. Em alguns momentos lembram os quartetos de Haydn. Nos movimentos lentos, porém, percebemos antes uma influência romântica e operística, numa atmosfera elegante da Belle Époque. Já os quartetos em Ré maior e Mi maior se encontram contextualizados no Romantismo, trabalham as frases melódicas mais longas. $\bigcirc$ Quarteto em Mi maior utiliza técnicas composicionais que remontam a Richard Wagner, por conta da densidade harmônica, envolta em cromatismos. Neste sentido, podemos falar de uma analogia com seu colega e amigo carioca, Francisco Braga, pois ambos foram admiradores de Wagner. Mesmo os estudantes 
de Paris ou Milão não escapavam à influência do grande compositor de óperas na Alemanha, naquela segunda metade do século XIX.

Dois quartetos foram apresentados na Itália, quando Meneleu ainda estudava no Conservatório Real de Milão. Posteriormente, os quatro quartetos foram executados em concertos na França, em São Paulo e no Rio de Janeiro, surpreendendo sempre por sua beleza e inspiração. $\bigcirc$ objetivo desde presente estudo, por certo, abrange também uma melhor inserção não apenas de Meneleu, mas dos demais compositores seus contemporâneos, tais como Antônio Carlos Gomes, Alexandre Levy, Leopoldo Miguez, Alberto Nepomuceno, Francisco Braga e Clauco Velasquez, entre outros, enquanto matéria obrigatória de música de câmara em meio às instituições de ensino do Brasil, e mesmo de outros países.

Os quartetos da Escola de Haydn (do assim chamado estilo clássico, do qual fazem parte também Mozart e Beethoven) são imprescindiveis para o desenvolvimento dos alunos e estudantes, nas escolas de música e nas universidades, por conta de toda uma questão estilística que contemplam em sua performance. Destacamos, contudo, o cuidado de Menelev ao elaborar seus quartetos, sua abordagem técnicoestilística, trabalhando magistralmente as quatro vozes instrumentais, bem como os uníssonos nas frases longas, intercalados com fugas, onde se exige dos intérpretes-executantes um bom conhecimento estrutural, para que saibam, de modo consciente, salientar as singularidades expressivas da linguagem. Por certo, os quartetos de Meneleu podem auxiliar didaticamente no desenvolvimento técnico-artístico dos alunos e estudantes que atuam em quartetos e demais música de câmara em nossas instituições acadêmicas. A exemplo de quartetos deste período, como os quartetos de Verdi, Gounod, e mesmo a Sonata para Cordas de Carlos Gomes, Meneleu nos envolve com temas operísticos, onde a singeleza e a dramaticidade se intercalam, viabilizando atmosferas sonoras instigantes. 


\section{Edição crítica das partituras, gravação integral dos quartetos}

Recebemos, do Museu da UFPA, o conjunto de fontes na forma de solfas: tanto os manuscritos das partituras como das partes individuais. Realizamos uma edição crítica, corrigindo disparidades entre os manuscritos das grades e das partes - dadas suas péssimas condições. Alguns quartetos contemplam versões diversas. Pareceu-nos que o compositor talvez tivesse dúvidas quanto à melhor alternativa. Este foi o primeiro desafio, analisar as diversas versões, concluir a edição completa dos movimentos, ensaiar, estudar as diversas questões da práxis em meio à poética de Menelev e decidir, por fim, qual a melhor opção para esta que acabou sendo a primeira gravação destas obras. A edição do Quarteto em Lá maior talvez tenha sido a mais difícil, neste sentido.

No Quarteto em Ré maior tínhamos duas versões completas do quarto movimento. A escolha se deu pelo estudo da poíesis (elaboração composicional) de Meneleu, buscando similaridades na escritura musical com outros movimentos. Para se ter uma ideia, a versão que não foi escolhida era composta por escalas e arpejos paralelos, nem sempre apresentando um discurso pautado pela inspiração e cantilenas como nos outros movimentos. A versão que escolhemos foi talvez a primeira a ser composta, provavelmente junto com os demais movimentos, parecendo-nos mais adequada. Julgamos ainda seu discurso musical mais interessante, mais bem desenvolvido, trabalhando intensamente as quatro vozes do quarteto.

trabalho crítico-editorial com estas partituras de Meneleu nos levou a decidir entre as possiveis alternativas, por conta dos conflitos entre as fontes, até mesmo com diferenças de notas, sem esquecer a ausência de articulações e dinâmicas. Refizemos e adequamos as articulações e dinâmicas, observando as questões poéticas e estilísticas de cada 
quarteto e movimento, a exemplo da escritura dos quartetos de Haydn, Mozart, Beethoven, Schubert e Mendelssohn, entre outros. Nas partituras de alguns quartetos havia tão somente notas escritas no pentagrama, isto é, sem demais notações, tais como articulação, dinâmica, fraseado e ligaduras. Em outros locais, só alguns compassos com ligaduras de fraseado. No que se refere às dinâmicas, observamos algumas propostas escritas a lápis nas partes, com indicações em italiano, as quais nos fizeram supor sua execução na Itália ou por músicos italianos. A adequação de dinâmicas foi estabelecida nos quatro quartetos gravados, lembrando que mesmo os grandes compositores nem sempre trabalham com tal nível de detalhamento. Neste caso, como estamos reconstruindo a memória de um compositor brasileiro, cujas obras julgamos importantes para o repertorio camerístico, deliberamos por uma edição a mais completa possivel, inclusive com sugestões de arcadas.

A integral dos quartetos de cordas de Meneleu Campos, cuja gravação pelo Quarteto Carlos Comes se deu no Estúdio Monteverdi, em São Paulo, foi lançada a 17 de setembro de 2021 , num projeto do Selo SESC - já disponível nas plataformas digitais.

\section{Considerações finais}

Meneleu Campos foi um dos principais compositores do Romantismo musical brasileiro - não merece permanecer esquecido. Seus quartetos não foram mais apresentados desde a década de 1920, daí a importância agora de sua inclusão no repertorio camerístico, para que sejam programados, esperamos, por conta da gravação pelo Quarteto Carlos Comes e da edição crítica de suas partituras e partes, trabalho capitaneado por Cláudio Cruz. 


\section{Referências}

Acervo do Museu da Universidade Federal do Pará.

Acervo da Biblioteca Nacional.

BARBOSA, Mário Alexandre Dantas. Meneleu Campos e a Educação Musical: as publicações de caráter didatico. Salvador: XVIII Congresso da Associação Nacional de Pesquisa e Pós-Graduação (ANPPOM) 2008, p. 275-279. Disponivel em https://anppom.org.br/anais/ anaiscongresso_anppom_2008/comunicas/COM450\%20-\%20Barbosa. pdf.

BARBOSA, Mário Alexandre Dantas. O Tango Brasileiro (18971915), de Meneleu Campos: redirecionamento estético e flexibilidade frente aos desafios profissionais. Rio de Janeiro: Anais da IV SIMPOM, $n^{\circ 0}$ 4, 2016, p. 502-512. Disponivel em http://www.seer.unirio.br/simpom/ article/view/5698/5133.

BOSIO, Etore. Traços artísticos e biographicos apreciações sobre suas obras muscais. Belém do Pará: Gillet, $\quad$ 1922. http://www.fcp.pa.gov.br/obrasraras/file/livros/ tracosartisticosebiographicosdomaestroettorebosio $1922 /$

Catalogo dei libretti di LUIGI ILLICA Castell'Arquato (Piacenza), 9 maggio 1857 - Colombarone (Piacenza), 16 dicembre 19/9. In: Opera liber - biblioteca digitale del libretto d'opera. https://web. archive.org/web/20 | 407 | 4 | 1 0922/http:// 193.204.255.27/operaliber/ index.php?page $=\% 2$ FoperaLiber\%2Flllica

CERNICCHIARO, Vincenzo. Storia della musica nel Brasile - dai tempi coloniali sino ai nostri giorni ( 1549- 1925). Milano: Fratelli Riccioni, 1926.

COSTA, Dayse Dias Silva e. Duração e Memoria: Bergoismo e o Piano no Concerto em Lá Maior para piano com acompanhamento de orquestra de Octávio Meneleu Campos. Dissertação de mestrado. João 
Pessoa: Centro de Ciências, Letras Humanas e Artes da Universidade Federal da Paraíba, 2011.

PARACAMPO, Amanda Brito. As trilhas amazônicas de Ettore Bosio. Dissertação de mestrado. Belém: Instituto de Filosofia e Ciências Humanas, 2018 . https://pphist.propesp.ufpa.br/ARQUIVOS/dissertacoes/ AS\%2OTRILHAS\%2OAMAZ\%C3\%94NICAS\%2ODE\%2OETTORE\%2OBOSIOAmanda\%2OB\%2OParacampo.pdf

PASCOA,MárcioLeonelFariasReis; SILVA,RossiniRochada.Patrimônio musical do Norte do Brasil - um estudo preliminar da ópera Cli eroi de Meneleu Campos (1872-1927). In: Revista ARETEÉ - Revista Amazônica de Ensino de Ciências, Volume 2, n² 2. Manaus: Universidade do Estado do Amazonas, 2008. https://www.yumpu.com/pt/document/read/26883991/ um-estudo-preliminar-da-opera-gli-eroi-de-meneleu-campos

RICCIARDI, Rubens Russomanno. A integra dos quartetos de cordas de Meneleu Campos - o reencontro com um grande compositor romântico belenense. CD: Meneleu Campos - Quarteto Carlos Comes. São Paulo: Selo SESC, 200l. Disponivel em https://www.sescsp.org.brl online/selo-sesc/1050_MENELEU+CAMPOS\#/tagcloud=lista

\section{Sobre os autores}

\section{Claudio Cruz}

Iniciou-se na música com seu pai, posteriormente recebeu orientações de Erich Lenninger, Maria Vischnia (violino) e George Olivier Toni (Teoria e Regência). Foi premiado pela Associação Paulista de Críticos de Artes (APCA), Prêmio Carlos Comes, Prêmio Bravo, Grammy Awards entre outros. Participou de diversos Festivais de Música, Festival Internacional de Campos de Jordão, Festival de Verão da Carinthia (Áutria) e Festival Internacional de Música de Cartagena, Festival Internacional La Música (Sarasota- EUA) entre outros. De 1990 a 2014 ocupou o cargo de Spalla da Osesp. Foi Regente Titular das Sinfônicas de Ribeirão Preto, Campinas e da Orquestra Sinfonica do Teatro Municipal do Rio de Janeiro, atualmente é Primeiro violino do Quarteto Carlos Comes, Regente e Diretor Musical da Orquestra Jovem do 
Estado de SP. Em sua discografia destacam-se os Concertos de Bruch, Tchaikovsky, Ronaldo Miranda e Fantasia de Almeida Prado gravados com a Osesp, Duo de Kodaly gravado com Antônio Meneses (Selo Avie), CD com obras brasileiras gravado na Itália (Selo Dynamic), CDs de compositores brasileiros gravados pelo Quarteto Carlos Comes entre outros.

Em 2021 lançou os trios de Villa-lobos com Antônio Meneses e Ricardo Castro, álbuns com os pianistas Marcelo Bratke e Olga Kopylova e os Quartetos de Meneleu Campos com o Quarteto Carlos Gomes selo Sesc.

\section{Odair Aparecido de Paula}

Graduou-se em História pela Universidade de Mogi das Cruzes em 1998 e Mestrado em Educação pela Pontifícia Universidade Católica - SP, em 2011. Atuou como pesquisador na área esportiva pelo Clube Esperia entre 1998 e 2014. Integrou a equipe de pesquisadores no projeto Resgate "Barão do Rio Branco" - Brasil 500 anos - seção Espanha, em 2000. Foi técnico de pesquisa no projeto "Mapeamento e Resgate de Aspectos da Cultura Tradicional de Comunidades Afrodescendentes de Mogi das Cruzes", Casa do Congado - Iphan - Crespial - UNESCO (2014-2015). Integra o projeto "Águas da Mantiqueira", sob os auspícios da Fundação Toyota Brasil e FUNDEPAC, desde 2016, e da Casa do Congado, desde 2014 , entidade responsável por pesquisas relacionadas aos grupos tradicionais afro descentes de Mogi das Cruzes (SP). Atualmente é professor e gestor da rede pública de ensino do Estado de São Paulo.

Recebido em 11/10/2021

Aprovado em 01/11/2021 